Published in final edited form as:

Heart Fail Clin. 2014 April ; 10(2): 243-250. doi:10.1016/j.hfc.2013.10.001.

\title{
Sleep Disordered Breathing in Patients with Heart Failure
}

\author{
Robert J. Mentz, MD and Mona Fiuzat, PharmD \\ Duke University Medical Center and Duke Clinical Research Institute, Durham, NC
}

\section{Synopsis}

Despite high adverse event rates in heart failure patients, the development of new therapies has slowed, and most recent studies have been neutral. This suggests the need for a reappraisal of treatment strategies, and a focus on co-morbid conditions in these patients. Sleep disordered breathing (SDB) is prevalent in heart failure patients and is associated with increased morbidity and mortality. SDB is pro-inflammatory, with nocturnal oxygen desaturations and hypercapnia appearing to play a pivotal role in the development of oxidative stress and sympathetic activation. Preliminary data suggest that attention to the diagnosis and management of SDB in heart failure patients may improve outcomes. Ongoing research into the roles of comorbidities such as SDB as a treatment target may lead to better clinical outcomes and improved quality of life for heart failure patients.

\section{Keywords}

co-morbidities; sleep apnea; heart failure; clinical trials

\section{Introduction}

Although there have been important successes in the development of therapies for chronic heart failure (HF) in recent decades, most recent HF trials have failed to show added benefit from new therapies ${ }^{1-3}$ and adverse event rates remain high. In particular, there has been little progress in the development of new therapies for acute $\mathrm{HF}^{4}$. This lack of progress suggests the need for a critical reappraisal of treatment strategies in HF, including treating comorbidities.

The presence of comorbidities in HF patients has been associated with significantly increased morbidity and mortality ${ }^{5}$. The risk of hospitalization markedly increases with the number of non-cardiovascular chronic conditions ${ }^{6}$. Rehospitalization rates following acute $\mathrm{HF}$ are nearly as high for non-cardiovascular causes as for $\mathrm{HF}^{7}$. Comorbid pulmonary and renal dysfunction along with sleep disordered breathing (SDB) complicate the management of HF patients. In this review, we summarize the impact of SDB on the characteristics, treatment and outcomes of HF patients. We also review data investigating the treatment of SDB in HF patients and identify areas for future research.

\footnotetext{
(c) 2013 Elsevier Inc. All rights reserved.

Corresponding Author: Dr. Robert Mentz. Duke University Medical Center, 2301 Erwin Road, Durham, NC 27710. Phone: 919-668-7121. Fax: 919-681-7755. robert.mentz@duke.edu.

Disclosures: M.F. - Research funding and consulting from ResMed Corporation. R.M. - no relevant disclosures.

Publisher's Disclaimer: This is a PDF file of an unedited manuscript that has been accepted for publication. As a service to our customers we are providing this early version of the manuscript. The manuscript will undergo copyediting, typesetting, and review of the resulting proof before it is published in its final citable form. Please note that during the production process errors may be discovered which could affect the content, and all legal disclaimers that apply to the journal pertain.
} 


\section{Epidemiology and Definitions}

SDB is common in patients with $\mathrm{HF}^{8}$. It occurs in up to $50-80 \%$ of $\mathrm{HF}$ patients ${ }^{9}$ and is highly prevalent in both those with preserved and reduced ejection fraction (EF). Two primary types of SDB occur in HF patients: obstructive sleep apnea (OSA) and central sleep apnea/Cheyne-Stokes Respiration (CSA/CSR). The prevalence of SDB in HF patients is substantially higher than in the general community where $\sim 18 \%$ of subjects exhibit OSA (2:1 male predominance) and $<1 \%$ have $\mathrm{CSA}^{10}$.

OSA involves repeated collapse of the pharynx that triggers apneas during sleep ${ }^{9,11}$ (Table 1). Apnea is defined as a $>90 \%$ reduction in tidal volume lasting $\geq 10$ seconds, and hypopnea is a reduction in tidal volume of $50 \%$ to $90 \%$, lasting $\geq 10$ seconds accompanied by a $\geq 3 \%$ decrease in oxyhemoglobin saturation or termination by arousal from sleep. A sleep breathing disorder is defined as the presence of $\geq 5$ episodes of apnea or hypopnea per hour of sleep (i.e., apnea-hypopnea index [AHI]), which is accompanied by either hypersomnolence or at least 2 episodes of choking or gasping during sleep, recurrent awakenings, unrefreshing sleep, daytime fatigue, or impaired concentration or memory. The AHI is used to grade severity as mild (6-14 episodes/hr), moderate (15 episodes/hr) or severe ( $\geq 30$ episodes $/ \mathrm{hr}$ ). OSA involves reduction in the tidal volume in the setting of typical breathing efforts, while CSA involves apnea for $\geq 10$ seconds without typical efforts as diagnosed on polysomnography. CSA and OSA rarely occur together in normal subjects, but commonly coexist in HF patients, although one pattern usually predominates ${ }^{12}$.

One study of 700 stable outpatients with HF with reduced EF (HFrEF) and New York Heart Association (NYHA) class $\forall$ II symptoms demonstrated that $76 \%$ of patients exhibited SDB with a breakdown of CSA and OSA in $40 \%$ and $36 \%$ of patients, respectively ${ }^{13}$. In particular, CSA seemed to be a marker of HF severity given the association with worse NYHA functional class and lower EF. However, the prevalence of SDB is high even in those with milder HF symptoms ${ }^{14}$. SDB has been shown to be at least as common in acute HF patients as in chronic HF patients ${ }^{15}$. Strikingly, in one study of acute HF patients, nearly all hospitalized patients had evidence of SDB with a mean AHI of 41 and $50 \%$ of total sleep time in Cheyne-Stokes respiration ${ }^{16}$. Acute treatment of HF also did not appear to consistently improve SDB. Women with HF may be less likely to have SDB compared to men and the severity of SDB may be lower ${ }^{17}$. HF with preserved EF (HFpEF) patients have a similarly high prevalence of SDB compared to those with $\mathrm{HFrEF}^{18,19}$. However, the breakdown between the predominant type of SDB in HFpEF may favor OSA rather than CSA as in HFrEF patients ${ }^{20}$.

Risk factors for the development of SDB in HF patients include male sex and increased age for both types of $\mathrm{SDB}^{21,22}$ (Table 2). Elevated body mass index (BMI) is an additional risk factor for OSA (perhaps only in men), while atrial fibrillation, hypocapnia during wakefulness ( $\mathrm{PCO} 2<38 \mathrm{mmHg}$ ), and severe left ventricular impairment increase the likelihood of $\mathrm{CSA}^{8,21}$.

OSA has been associated with increased morbidity and mortality in the general population ${ }^{23-25}$. In acute HF patients, SDB is an independent predictor of cardiac readmission ${ }^{26}$. In chronic HF patients, untreated moderate to severe OSA was associated with increased mortality on multivariable analysis in a small study of 164 patients ${ }^{27}$ (Figure 1). CSA has also been shown to be a predictor of mortality in $\mathrm{HFrEF}^{28}$ with increased risk at higher AHI values ${ }^{29}$. Another study found that the risk associated with SDB was confined to those with ischemic etiology of $\mathrm{HF}^{30}$. In contrast, Roebuck et al did not find increased longterm mortality associated with OSA in patients with $\mathrm{HF}^{31}$. Thus, the question of independent risk conferred by SDB in HF requires further study. 


\section{Pathophysiological Interactions}

The pathophysiology of OSA and CSA are distinct. OSA is primarily a failure to maintain airway patency, although abnormal respiratory feedback loops may play a role in HF patients ${ }^{32,33}$. In the general population, OSA patients tend to have a smaller upper airway which may be exacerbated by the nocturnal response of the pharyngeal dilator muscles to negative pressure and increasing carbon dioxide. Unfavorable upper airway anatomy may be due to acquired conditions such as obesity or intrinsic structural abnormalities which may be further compromised by poor sleep posture. However, in HF patients, the AHI has a much weaker correlation with $\mathrm{BMI}^{34}$. Thus, it has been suggested that factors other than obesity may play a prominent role in the development of OSA in HF patients. These mechanisms may include nocturnal rostral fluid movement with increased pharyngeal obstruction ${ }^{35}$. In fact, apnea type and severity varies according to fluctuations in volume status and the degree of cardiac dysfunction ${ }^{36}$. With greater fluid accumulation, patients transition from predominantly OSA to $\mathrm{CSA}^{35}$. In a given night, the proportion of OSA events may decrease over time with a concomitant rise in the proportion of CSA events ${ }^{12}$.

CSA is mainly due to the instability of the ventilatory control systems ${ }^{33}$. Breathing is controlled by a feedback loop where an increase in the arterial partial pressure of carbon dioxide $\left(\mathrm{PaCO}_{2}\right)$ stimulates breathing and a decrease inhibits it. In healthy individuals, this maintains the $\mathrm{PaCO}_{2}$ within a narrow range. However, HF patients have enhanced central chemoreceptor sensitivity which results in a significantly larger ventilatory response to carbon dioxide ${ }^{37,38}$. This hyperventilatory response, which is further exacerbated in the setting of an elevated pulmonary capillary wedge pressure, may lower the carbon dioxide value below the apneic threshold with resultant central apnea ${ }^{39}$. Circulation time is also increased in HF due to reduced cardiac output, which delays the sensing of alterations in $\mathrm{PaCO}_{2}$ by the central chemoreceptors. The enhanced response to carbon dioxide and hyperventilation in response to pulmonary congestion appear to be instrumental in the development of CSA while the circulation time influences the resultant breathing pattern ${ }^{33}$.

Chronic SDB causes a series of derangements that may lead to the development or exacerbation of HF (Figure 2). SDB is pro-inflammatory, with nocturnal oxygen desaturations and hypercapnia appearing to play a pivotal role in the development of oxidative stress and sympathetic activation ${ }^{9}$. Patients with ischemic cardiomyopathy may be more susceptible to these adverse consequences than those with non-ischemic etiology ${ }^{30}$. Hypertension, diabetes, coronary artery disease, and atrial fibrillation—all well-established HF risk factors-are also adversely impacted by $\mathrm{SDB}^{40-43}$. Thus, the pathophysiology of $\mathrm{HF}$ and SDB are intertwined with each contributing to the development and progression of the other.

\section{Diagnostic issues}

SDB cannot be diagnosed in HF patients by symptoms or by routine cardiac assessment ${ }^{14}$. SDB is diagnosed by overnight polysomnography in a sleep laboratory with documentation of sleep architecture, cardiac rhythm, oxygenation, airflow, and thoracoabdominal movements. Portable monitoring devices may be used as an alternative, if diagnosis via polysomnography is inaccessible or unfeasible ${ }^{44}$. Despite the high prevalence of SDB in HF patients, it is under-diagnosed as SDB symptoms are less common than in the general population $^{33}$. For instance, HF patients with SDB have less subjective daytime sleepiness. On the Epworth Sleepiness Scale (ESS), a common metric used to characterize sleep disorders, they have lower scores (i.e., less sleepy) at any given AHI compared to those without $\mathrm{HF}^{34}$. There is also no significant relationship between the ESS and increasing AHI in the HF population. For any given AHI, patients with HF have a longer sleep-onset 
latency, and less sleep than the general population despite reporting less sleepiness. Thus, a clinician's level of suspicion for SDB based on a patient's symptom complex or scores on standard sleep metrics may be lower for HF patients compared to the general population, despite the potential severity of the underlying disorder. Diagnosis is further hampered by the absence of a simple and accurate screening tool and limited access to sleep facilities in the large numbers of patients with HF.

\section{Therapeutic issues}

Since OSA and CSA have different causes, therapy may differ for the disorders. At present, the primary treatment for OSA is continuous positive airway pressure (CPAP). Several small, short-duration studies demonstrated that CPAP therapy in HF patients with OSA reduced sympathetic activity with associated decreases in blood pressure and heart rate ${ }^{45,46}$, and also increased daytime heart rate variability suggesting improved vagal modulation ${ }^{47}$. Most studies exploring the impact of CPAP on cardiac function and symptoms have demonstrated a beneficial effect. For instance, CPAP has been shown to reduce left ventricular dimensions and improve $\mathrm{EF}$, cardiac efficiency, and quality of life ${ }^{46,48,49}$. In contrast, studies of the impact of CPAP on other surrogates such as hypertension and natriuretic peptide levels in HF patients have yielded variable results $46,48,50$.

While conventional CPAP has been shown to improve morbidity and possibly mortality in the general population ${ }^{23,51-53}$, its influence on outcomes in HF patients is less clear. Observational studies assessing the efficacy of CPAP on morbidity and mortality in chronic HF patients with OSA have suggested potential benefits ${ }^{9}$. Two small studies in HF patients with $>2$ years of follow-up suggested lower death or rehospitalization risk ${ }^{54}$ and a trend for reduced mortality in the CPAP treatment groups ${ }^{27}$. Large-scale, appropriately powered, randomized trials are needed to empirically demonstrate the benefit of CPAP in OSA patients with HF.

Since CSA may be related to the severity of HF, optimization of HF therapy may improve CSA. Observational studies suggest that diuretics, beta-blockers, and biventricular pacing may reduce the severity of CSA ${ }^{55}$. For instance, small, uncontrolled studies of the impact of biventricular pacing have suggested a potential benefit on $\mathrm{SDB}^{56}$, yet results have been conflicting ${ }^{57}$ and further study is required.

In contrast to OSA, the mechanisms by which CPAP may benefit the underlying pathophysiology of CSA is less clear given the lack of upper airway obstruction. However, CPAP may provide a hemodynamic benefit by reducing left ventricular afterload and cardiac filling pressures ${ }^{58}$. In a small study of 66 patients, Sin et al reported an improvement in EF and transplant-free survival in HF patients with CSA randomized to CPAP if they complied with treatment ${ }^{59}$. The largest randomized, prospective study was the CANPAP study (CANadian continuous Positive Airway Pressure for patients with heart failure and central sleep apnea) $(\mathrm{N}=258)$, which found no difference in 2-year survival with CPAP despite improvements in EF, norepinephrine levels and 6-minute walk distance ${ }^{60}$. However, the mean duration of nightly CPAP therapy was $\approx 4$ hours over 3 months and $<4$ hours at the 12-month follow-up. Furthermore, CPAP only reduced the mean AHI to 19. A post-hoc analysis suggested that responders to CPAP (i.e., improvement in AHI to $<15$ at $3 \mathrm{mos}$ ) had a significant improvement in EF and transplant-free survival compared to non-responders or controls ${ }^{61}$. The authors concluded that CPAP might improve outcomes if CSA is suppressed soon after its initiation. However, these results must be viewed as hypothesis-generating given the limitations of subgroup analyses. 
Minute ventilation-targeted adaptive servo-ventilation (ASV) is a distinct form of noninvasive ventilation that automatically adjusts the degree of pressure support in response to the patient's breathing efforts. ASV may treat both CSA and OSA with improved tolerability compared to CPAP devices. Previous HF studies have demonstrated benefits on quality of life, natriuretic peptide levels and left ventricular function with ASV ${ }^{62,63}$. A recent randomized trial of $23 \mathrm{HF}$ patients with CSA unsuppressed despite $\geq 3$ months of CPAP (defined as AHI $\geq 15$ ) demonstrated that ASV treatment was more effective at suppressing the AHI with a greater improvement in EF and better compliance compared to continued CPAP ${ }^{64}$. Yet, survival benefits from auto-titration devices in HF patients have not been demonstrated, and randomized trials of ASV in HF are ongoing. The Serve-HF trial (Treatment of Predominant Central Sleep Apnoea by Adaptive Servo Ventilation in Patients With Heart Failure) is an ongoing European trial in HF patients with reduced EF (target enrollment $\mathrm{N}=1313$ ) which will evaluate the long-term morbitity/mortality and costeffectiveness of ASV (ClinicalTrials.gov Identifier: NCT00733343).

\section{Clinical Perspective}

For patients with HF, there is a paucity of data from prospective, randomized, controlled trials addressing the potential benefits of treatment for either OSA or CSA. As such, there are no consensus guidelines endorsed by either sleep medicine or HF specialists on management strategies for SDB associated with HF. Nonetheless, observational data and preliminary randomized data suggest a role for the treatment of SDB in HF patients through optimization of standard guideline-based HF management and consideration of the use of non-invasive ventilation devices. The International Collaboration of Sleep Apnea Cardiovascular Trialists has recently summarized the current status of research in the field and highlighted future steps ${ }^{65}$.

\section{Summary}

We have highlighted the high prevalence and implications of SDB in HF patients and reviewed preliminary data suggesting that careful attention to the diagnosis and management of SDB may help to improve patient outcomes. The lack of recent progress in reducing the exceedingly high event rate in HF patients suggests the need for a reappraisal of treatment strategies, including treating comorbidities. A focus on SDB represents a logical consideration in the holistic management of HF patients given the closely inter-related nature of these conditions.

\section{Acknowledgments}

Funding Support: None

\section{References}

1. Massie BM, O'Connor CM, Metra M, et al. Rolofylline, an adenosine A1-receptor antagonist, in acute heart failure. N Engl J Med. 2010; 363(15):1419-1428. [PubMed: 20925544]

2. Gheorghiade M, Bohm M, Greene SJ, et al. Effect of aliskiren on postdischarge mortality and heart failure readmissions among patients hospitalized for heart failure: the ASTRONAUT randomized trial. JAMA. 2013; 309(11):1125-1135. [PubMed: 23478743]

3. Swedberg K, Young JB, Anand IS, et al. Treatment of anemia with darbepoetin alfa in systolic heart failure. N Engl J Med. 2013; 368(13):1210-1219. [PubMed: 23473338]

4. Felker GM, Pang PS, Adams KF, et al. Clinical Trials of Pharmacological Therapies in Acute Heart Failure Syndromes: Lessons Learned and Directions Forward. Circ Heart Fail. 2010; 3(2):314-325. [PubMed: 20233993] 
5. Mentz RJ, Felker GM. Noncardiac comorbidities and acute heart failure patients. Heart Fail Clin. 2013; 9(3):359-367. [PubMed: 23809421]

6. Braunstein JB, Anderson GF, Gerstenblith G, et al. Noncardiac comorbidity increases preventable hospitalizations and mortality among Medicare beneficiaries with chronic heart failure. J Am Coll Cardiol. 2003; 42(7):1226-1233. [PubMed: 14522486]

7. O'Connor CM, Miller AB, Blair JE, et al. Causes of death and rehospitalization in patients hospitalized with worsening heart failure and reduced left ventricular ejection fraction: results from Efficacy of Vasopressin Antagonism in Heart Failure Outcome Study with Tolvaptan (EVEREST) program. Am Heart J. 2010; 159(5):841-849. e841. [PubMed: 20435194]

8. Ferrier K, Campbell A, Yee B, et al. Sleep-disordered breathing occurs frequently in stable outpatients with congestive heart failure. Chest. 2005; 128(4):2116-2122. [PubMed: 16236863]

9. Kasai T, Bradley TD. Obstructive sleep apnea and heart failure: pathophysiologic and therapeutic implications. J Am Coll Cardiol. 2011; 57(2):119-127. [PubMed: 21211682]

10. Young T, Shahar E, Nieto FJ, et al. Predictors of sleep-disordered breathing in communitydwelling adults: the Sleep Heart Health Study. Arch Intern Med. 2002; 162(8):893-900. [PubMed: 11966340]

11. The Report of an American Academy of Sleep Medicine Task Force. Sleep-related breathing disorders in adults: recommendations for syndrome definition and measurement techniques in clinical research. Sleep. 1999; 22(5):667-689. [PubMed: 10450601]

12. Tkacova R, Niroumand M, Lorenzi-Filho G, et al. Overnight shift from obstructive to central apneas in patients with heart failure: role of PCO2 and circulatory delay. Circulation. 2001; 103(2):238-243. [PubMed: 11208683]

13. Oldenburg O, Lamp B, Faber L, et al. Sleep-disordered breathing in patients with symptomatic heart failure: a contemporary study of prevalence in and characteristics of 700 patients. Eur J Heart Fail. 2007; 9(3):251-257. [PubMed: 17027333]

14. Vazir A, Hastings PC, Dayer M, et al. A high prevalence of sleep disordered breathing in men with mild symptomatic chronic heart failure due to left ventricular systolic dysfunction. Eur J Heart Fail. 2007; 9(3):243-250. [PubMed: 17030014]

15. Khayat RN, Jarjoura D, Patt B, et al. In-hospital testing for sleep-disordered breathing in hospitalized patients with decompensated heart failure: report of prevalence and patient characteristics. J Card Fail. 2009; 15(9):739-746. [PubMed: 19879459]

16. Padeletti M, Green P, Mooney AM, et al. Sleep disordered breathing in patients with acutely decompensated heart failure. Sleep Med. 2009; 10(3):353-360. [PubMed: 18614398]

17. Paulino A, Damy T, Margarit L, et al. Prevalence of sleep-disordered breathing in a 316-patient French cohort of stable congestive heart failure. Arch Cardiovasc Dis. 2009; 102(3):169-175. [PubMed: 19375670]

18. Bitter T, Faber L, Hering D, et al. Sleep-disordered breathing in heart failure with normal left ventricular ejection fraction. Eur J Heart Fail. 2009; 11(6):602-608. [PubMed: 19468022]

19. Chan J, Sanderson J, Chan W, et al. Prevalence of sleep-disordered breathing in diastolic heart failure. Chest. 1997; 111(6):1488-1493. [PubMed: 9187161]

20. Herrscher TE, Akre H, Overland B, et al. High prevalence of sleep apnea in heart failure outpatients: even in patients with preserved systolic function. J Card Fail. 2011; 17(5):420-425. [PubMed: 21549300]

21. Sin DD, Fitzgerald F, Parker JD, et al. Risk factors for central and obstructive sleep apnea in 450 men and women with congestive heart failure. Am J Respir Crit Care Med. 1999; 160(4):11011106. [PubMed: 10508793]

22. Bradley TD, Floras JS. Sleep apnea and heart failure: Part I: obstructive sleep apnea. Circulation. 2003; 107(12):1671-1678. [PubMed: 12668504]

23. Marin JM, Carrizo SJ, Vicente E, et al. Long-term cardiovascular outcomes in men with obstructive sleep apnoea-hypopnoea with or without treatment with continuous positive airway pressure: an observational study. Lancet. 2005; 365(9464):1046-1053. [PubMed: 15781100]

24. Punjabi NM, Caffo BS, Goodwin JL, et al. Sleep-disordered breathing and mortality: a prospective cohort study. PLoS Med. 2009; 6(8):e1000132. [PubMed: 19688045] 
25. Gami AS, Olson EJ, Shen WK, et al. Obstructive Sleep Apnea and the Risk of Sudden Cardiac Death: A Longitudinal Study of 10,701 Adults. J Am Coll Cardiol. 2013

26. Khayat R, Abraham W, Patt B, et al. Central sleep apnea is a predictor of cardiac readmission in hospitalized patients with systolic heart failure. J Card Fail. 2012; 18(7):534-540. [PubMed: 22748486]

27. Wang H, Parker JD, Newton GE, et al. Influence of obstructive sleep apnea on mortality in patients with heart failure. J Am Coll Cardiol. 2007; 49(15):1625-1631. [PubMed: 17433953]

28. Javaheri S, Shukla R, Zeigler H, et al. Central sleep apnea, right ventricular dysfunction, and low diastolic blood pressure are predictors of mortality in systolic heart failure. J Am Coll Cardiol. 2007; 49(20):2028-2034. [PubMed: 17512359]

29. Lanfranchi PA, Braghiroli A, Bosimini E, et al. Prognostic value of nocturnal Cheyne-Stokes respiration in chronic heart failure. Circulation. 1999; 99(11):1435-1440. [PubMed: 10086966]

30. Yumino D, Wang H, Floras JS, et al. Relationship between sleep apnoea and mortality in patients with ischaemic heart failure. Heart. 2009; 95(10):819-824. [PubMed: 19131443]

31. Roebuck T, Solin P, Kaye DM, et al. Increased long-term mortality in heart failure due to sleep apnoea is not yet proven. Eur Respir J. 2004; 23(5):735-740. [PubMed: 15176689]

32. White DP. Pathogenesis of obstructive and central sleep apnea. Am J Respir Crit Care Med. 2005; 172(11):1363-1370. [PubMed: 16100008]

33. Ng AC, Freedman SB. Sleep disordered breathing in chronic heart failure. Heart Fail Rev. 2009; 14(2):89-99. [PubMed: 18548345]

34. Arzt M, Young T, Finn L, et al. Sleepiness and sleep in patients with both systolic heart failure and obstructive sleep apnea. Arch Intern Med. 2006; 166(16):1716-1722. [PubMed: 16983049]

35. Yumino D, Redolfi S, Ruttanaumpawan P, et al. Nocturnal rostral fluid shift: a unifying concept for the pathogenesis of obstructive and central sleep apnea in men with heart failure. Circulation. 2010; 121(14):1598-1605. [PubMed: 20351237]

36. Ryan CM, Floras JS, Logan AG, et al. Shift in sleep apnoea type in heart failure patients in the CANPAP trial. Eur Respir J. 2010; 35(3):592-597. [PubMed: 20190331]

37. Javaheri S. A mechanism of central sleep apnea in patients with heart failure. N Engl J MEd. 1999; 341(13):949-954. [PubMed: 10498490]

38. Dempsey JA. Crossing the apnoeic threshold: causes and consequences. Exp Physiol. 2005; 90(1): 13-24. [PubMed: 15572458]

39. Solin P, Bergin P, Richardson M, et al. Influence of pulmonary capillary wedge pressure on central apnea in heart failure. Circulation. 1999; 99(12):1574-1579. [PubMed: 10096933]

40. Punjabi NM, Beamer BA. Alterations in Glucose Disposal in Sleep-disordered Breathing. Am J Respir Crit Care Med. 2009; 179(3):235-240. [PubMed: 19011148]

41. Lavie P, Herer P, Hoffstein V. Obstructive sleep apnoea syndrome as a risk factor for hypertension: population study. BMJ. 2000; 320(7233):479-482. [PubMed: 10678860]

42. Gami AS, Pressman G, Caples SM, et al. Association of atrial fibrillation and obstructive sleep apnea. Circulation. 2004; 110(4):364-367. [PubMed: 15249509]

43. Peker Y, Carlson J, Hedner J. Increased incidence of coronary artery disease in sleep apnoea: a long-term follow-up. Eur Respir J. 2006; 28(3):596-602. [PubMed: 16641120]

44. Erman MK, Stewart D, Einhorn D, et al. Validation of the ApneaLink for the screening of sleep apnea: a novel and simple single-channel recording device. J Clin Sleep Med. 2007; 3(4):387-392. [PubMed: 17694728]

45. Usui K, Bradley TD, Spaak J, et al. Inhibition of awake sympathetic nerve activity of heart failure patients with obstructive sleep apnea by nocturnal continuous positive airway pressure. J Am Coll Cardiol. 2005; 45(12):2008-2011. [PubMed: 15963401]

46. Mansfield DR, Gollogly NC, Kaye DM, et al. Controlled trial of continuous positive airway pressure in obstructive sleep apnea and heart failure. Am J Respir Crit Care Med. 2004; 169(3): 361-366. [PubMed: 14597482]

47. Gilman MP, Floras JS, Usui K, et al. Continuous positive airway pressure increases heart rate variability in heart failure patients with obstructive sleep apnoea. Clin Sci (London). 2008; 114(3): 243-249. [PubMed: 17824846] 
48. Kaneko Y, Floras JS, Usui K, et al. Cardiovascular effects of continuous positive airway pressure in patients with heart failure and obstructive sleep apnea. N Engl J Med. 2003; 348(13):12331241. [PubMed: 12660387]

49. Yoshinaga K, Burwash IG, Leech JA, et al. The effects of continuous positive airway pressure on myocardial energetics in patients with heart failure and obstructive sleep apnea. J Am Coll Cardiol. 2007; 49(4):450-458. [PubMed: 17258090]

50. Smith LA, Vennelle M, Gardner RS, et al. Auto-titrating continuous positive airway pressure therapy in patients with chronic heart failure and obstructive sleep apnoea: a randomized placebocontrolled trial. Eur Heart J. 2007; 28(10):1221-1227. [PubMed: 17470670]

51. Doherty LS, Kiely JL, Swan V, et al. Long-term effects of nasal continuous positive airway pressure therapy on cardiovascular outcomes in sleep apnea syndrome. Chest. 2005; 127(6):20762084. [PubMed: 15947323]

52. Campos-Rodriguez F, Pena-Grinan N, Reyes-Nunez N, et al. Mortality in obstructive sleep apneahypopnea patients treated with positive airway pressure. Chest. 2005; 128(2):624-633. [PubMed: 16100147]

53. Campos-Rodriguez F, Martinez-Garcia MA, de la Cruz-Moron I, et al. Cardiovascular mortality in women with obstructive sleep apnea with or without continuous positive airway pressure treatment: a cohort study. Ann Intern Med. 2012; 156(2):115-122. [PubMed: 22250142]

54. Kasai T, Narui K, Dohi T, et al. Prognosis of patients with heart failure and obstructive sleep apnea treated with continuous positive airway pressure. Chest. 2008; 133(3):690-696. [PubMed: 18198253]

55. Olson LJ, Somers VK. Treating central sleep apnea in heart failure: outcomes revisited. Circulation. 2007; 115(25):3140-3142. [PubMed: 17592088]

56. Stanchina ML, Ellison K, Malhotra A, et al. The impact of cardiac resynchronization therapy on obstructive sleep apnea in heart failure patients: a pilot study. Chest. 2007; 132(2):433-439. [PubMed: 17573498]

57. Oldenburg O, Faber L, Vogt J, et al. Influence of cardiac resynchronisation therapy on different types of sleep disordered breathing. Eur J Heart Fail. 2007; 9(8):820-826. [PubMed: 17467333]

58. Bradley TD, Floras JS. Sleep apnea and heart failure: Part II: central sleep apnea. Circulation. 2003; 107(13):1822-1826. [PubMed: 12682029]

59. Sin DD, Logan AG, Fitzgerald FS, et al. Effects of continuous positive airway pressure on cardiovascular outcomes in heart failure patients with and without Cheyne-Stokes respiration. Circulation. 2000; 102(1):61-66. [PubMed: 10880416]

60. Bradley TD, Logan AG, Kimoff RJ, et al. Continuous positive airway pressure for central sleep apnea and heart failure. N Engl J Med. 2005; 353(19):2025-2033. [PubMed: 16282177]

61. Arzt M, Floras JS, Logan AG, et al. Suppression of central sleep apnea by continuous positive airway pressure and transplant-free survival in heart failure: a post hoc analysis of the Canadian Continuous Positive Airway Pressure for Patients with Central Sleep Apnea and Heart Failure Trial (CANPAP). Circulation. 2007; 115(25):3173-3180. [PubMed: 17562959]

62. Sharma BK, Bakker JP, McSharry DG, et al. Adaptive servoventilation for treatment of sleepdisordered breathing in heart failure: a systematic review and meta-analysis. Chest. 2012; 142(5): 1211-1221. [PubMed: 22722232]

63. Pepperell JC, Maskell NA, Jones DR, et al. A randomized controlled trial of adaptive ventilation for Cheyne-Stokes breathing in heart failure. Am J Respir Crit Care Med. 2003; 168(9):1109_ 1114. [PubMed: 12928310]

64. Kasai T, Kasagi S, Maeno K-i, et al. Adaptive Servo-Ventilation in Cardiac Function and Neurohormonal Status in Patients With Heart Failure and Central Sleep Apnea Nonresponsive to Continuous Positive Airway Pressure. JACC: Heart Fail. 2013; 1(1):58-63. [PubMed: 24621799]

65. Gottlieb DJ, Craig SE, Lorenzi-Filho G, et al. Sleep Apnea Cardiovascular Clinical Trials-Current Status and Steps Forward: The International Collaboration of Sleep Apnea Cardiovascular Trialists. Sleep. 2013; 36(7):975-980. [PubMed: 23814333] 


\section{Key Points}

- Sleep disordered breathing is prevalent in heart failure patients and is associated with increased morbidity and mortality.

- Sleep disordered breathing is pro-inflammatory, with nocturnal oxygen desaturations and hypercapnia playing a role in the development of oxidative stress and sympathetic activation.

- Attention to the diagnosis and management of sleep disordered breathing in heart failure patients may improve outcomes. 


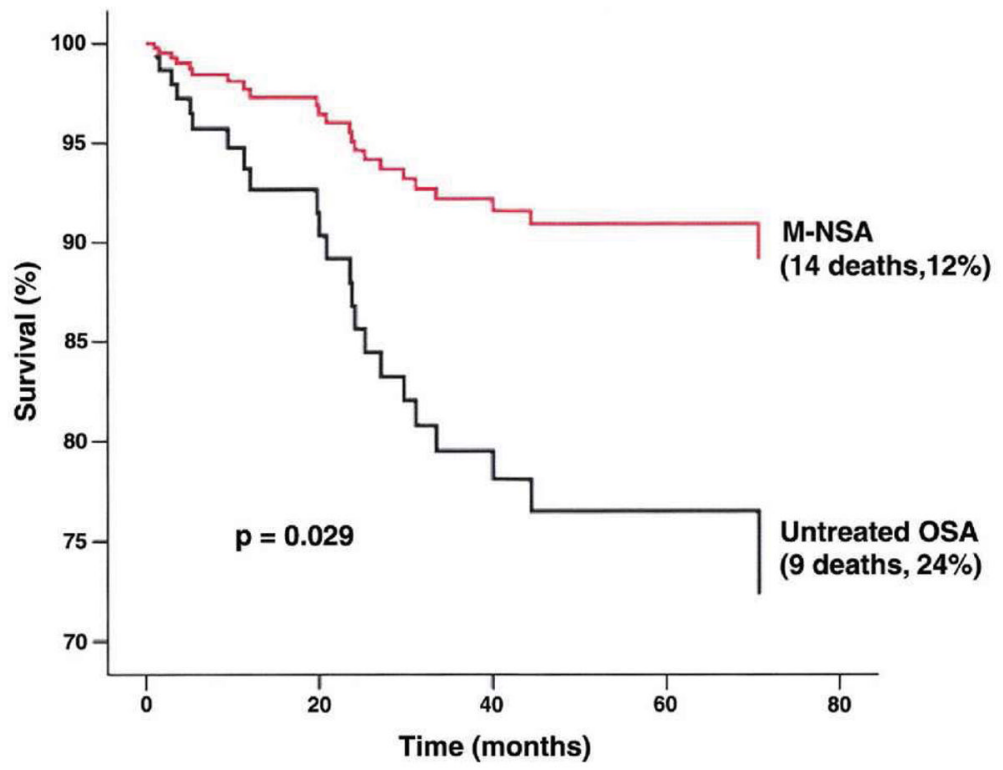

Figure 1.

Multivariable Cox Proportional Hazards Survival Plots for Patients With Mild to No Sleep Apnea Versus Untreated Obstructive Sleep Apnea. Multivariable Cox proportional hazards plots showing worse survival of heart failure patients with untreated obstructive sleep apnea (OSA) than in those with mild to no sleep apnea $(\mathrm{M}-\mathrm{NSA})$ (hazard ratio $=2.81, \mathrm{p}=0.029$ ) after adjusting for significant confounders (left ventricular ejection fraction, New York Heart Association functional class, and age). The adjusted survival curves are shown at the average values of these confounders. From Wang $\mathrm{H}$ et al. Influence of obstructive sleep apnea on mortality in patients with heart failure. J Am Coll Cardiol 2007;49(15):1625-1631; with permission. 


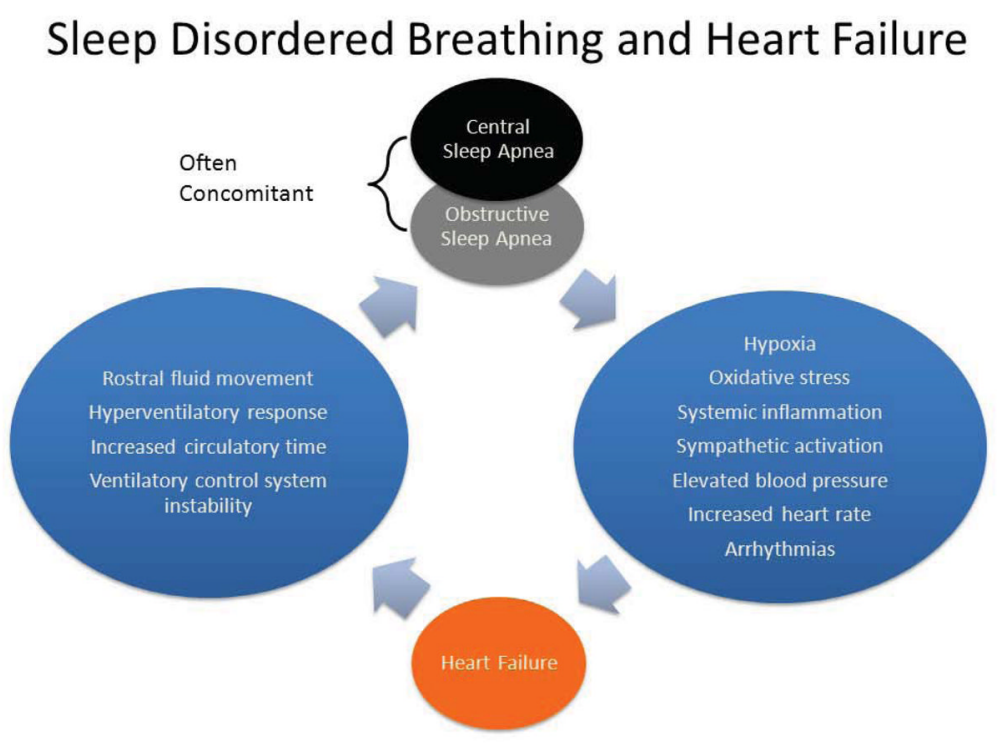

Figure 2.

Interaction of the pathophysiology of sleep disordered breathing and heart failure. 
Table 1

Definitions of Sleep Disordered Breathing.

Apnea

- $\quad$ A $>90 \%$ reduction in tidal volume lasting $\geq 10$ seconds

Hypopnea

- A reduction in tidal volume of $50 \%$ to $90 \%$ that lasts $\geq 10$ seconds

- Accompanied by a $23 \%$ decrease in oxyhemoglobin saturation $(\mathrm{SaO} 2)$ or termination by arousal from sleep

Sleep Breathing Disorder

- $\quad 25$ episodes of apnea or hypopnea per hour of sleep

- Accompanied by either hypersomnolence or at least 2 episodes of choking or gasping during sleep, recurrent awakenings, unrefreshing sleep, daytime fatigue, or impaired concentration or memory

Obstructive Sleep Apnea

- $\quad$ Repeated collapse of the pharynx that triggers apneas during sleep

- Reduction in the tidal volume with apneas and/or hypopneas in the setting of typical breathing efforts

Central Sleep Apnea

- Apneas for $\geq 10$ seconds without typical breathing efforts 
Table 2

Risk factors for sleep disordered breathing.

\begin{tabular}{|c|c|c|}
\hline $\begin{array}{l}\text { Both Obstructive and Central Sleep } \\
\text { Apnea }\end{array}$ & Obstructive Sleep Apnea & Central Sleep Apnea \\
\hline $\begin{array}{ll}\text { - } & \text { Male sex } \\
\text { - } & \text { Increased age }\end{array}$ & $\begin{array}{l}\text { - Elevated body mass index } \\
\text { (possibly men only) }\end{array}$ & $\begin{array}{ll}\text { - } & \text { Atrial fibrillation } \\
\text { - } & \text { Hypocapnia during wakefulness } \\
\text { - } & \text { Severe left ventricular impairment }\end{array}$ \\
\hline
\end{tabular}

